\title{
Towards More Convenient Livable City: Research on the Suburban Dweller Space Using Behavior Through Spatiotemporal Big Data
}

\author{
Ruiqi SUN, Southeast University, China \\ Yi SHI, Southeast University, China
}

\begin{abstract}
Under the background of the rapid urbanization, suburbs have become the forefront of urban living space. Compared with the dwellers in the city center, the daily behavior characteristics of suburban dwellers are more varied due to the commuting distance and employment opportunities. Thus, if the city governor only based on the socio-economic or population density index to allocate the public resources, it might result waste. In here, we attempt to discuss the approach to reduce this kind of waste through dynamic behavior perspectives. Based on the above, Shenyang (the provincial capital city which located in the Northeast of China) was selected as a sample. The research collected LBS (Location Based Service) big data of 24 hours for seven consecutive days. Based on ST-DBSCAN clustering algorithm, the movement trajectories and stop points of 818 suburban dwellers in southern suburbs were recognized. Then, the activity type of each stop point was identified with time-space threshold method, including working behavior, residential behavior, non-work behavior outside home. Afterwards, based on the time rhythm characteristics of working and residential behaviors, the dwellers were divided in four types of daily activity patterns: Normal-time-rhythm group, Early-time-restricted-rhythm group Late-time-restricted-rhythm group, Dual-time-restricted-rhythm group. Based on the classification, the spatio-temporal distribution of the daily space of the residents during the weekdays and weekends are measured, the methods of geo-visualization and analysis of variance are applied to compare the differences in the daily activity space of different groups. The result indicated that the time constraints indeed affect the spatio-temporal distribution of non-working behaviors outside home in different ways, which further affects the use of city and community functional space. The finding focus on the different demands of groups of different lifestyles, providing a certain reference for the facilities time management and optimization of public facilities configuration policy.
\end{abstract}

\section{Keywords}

suburban dweller, spatiotemporal behavior, activity space, urban big data 


\section{Introduction}

Under the background of the rapid urbanization, suburbs have become the forefront of urban living space. The difference in land location, the development of rapid rail transit, the guidance of government policies caused various factors such as population, industries, service facilities, and transportation to gather in the suburbs, which promoted the reconstruction of urban space and the formation of urban regions. Compared with the urban areas in the central of the city, the spatial types of suburbs are more heterogeneous(Bin, 2009), the differences in social and economic attributes of residents are more obvious, and the population composition is relatively mixed(Wang et al., 2003), the job-resident relationship is more diverse. Various phenomena caused by suburbanization have always been the focus of urban geography, urban planning and transportation. With the humanistic and behavioral turn of human geography, the study of the activity space that emphasizes the individual and micro-process provides an important perspective for understanding the interaction between human activities and the built environment in terms of time and space(Zhang $Y, 2013)$. The activity space of individuals reflects their use of different types of space in the city. Many scholars have used socio-economic and demographic variables to identify individuals or family groups with similarities to analyse the temporal and spatial distribution of different groups behavior, so as to provide suggestions or references for the optimization of service facilities, the type and quantity of occupational posts, the planning of the overall urban spatial structure and so on. Shen (2013)combined questionnaire surveys with GPS technology ,measuring the daily activity space of suburban dwellers and studying the utilization of urban space and case community space on weekdays and weekend. Xu et al(2015) analysed the spatial differences of home-based activities among people in different regions of Shenzhen, finding that there are very obvious differences between north and south, which is consistent with the city's economic and transportation development. Zhang (2019) measured the activity space of residents living in different housing types, finding that the activity space isolation characteristics are also different between different days of the week. Although suburban dwellers may live in adjacent areas, due to differences in their own attributes and subjective will, there are significant differences in their lifestyles and using way of urban space. The personal lifestyle reflects the coordination and arrangement of the individual's daily activities, the role and responsibilities of the individual in the family, it is the result of the comprehensive effect of time and space constraints. And proposed The "new mobility" paradigm proposed by Sheller and Urry (2006) further emphasizes that social science research should integrate human mobility and consider the dimension of time, and the classification of population types should take the activity-travel patterns of people into consideration. Jiang (2012) used the data from the travel survey of the Chicago metropolitan area and explores the inherent daily activity structure of individuals, enriching the crowd classification methods from the perspective of individual behavior clusters. Lin(2009) used the method of factor analysis, dividing the population into groups according to the economic and demographic characteristics of the individual along with the mode of activity, then separately developed the travel demand model based on the classification result. Classifying the population from the perspective of individual behaviors is conducive to a deeper understanding of the relationship between the urban spatial structure and crowd activities, thus helping policy makers develop more precise strategies for land use and transportation planning.

Existing research on the measurement of daily behavior and daily activity space largely relies on demographic statistics, questionnaire surveys, travel logs and other methods to assess the dynamic distribution of crowds' behavior. The method of combining GPS and questionnaire has been implemented in many cases. However, It is difficult to fully depicting the living area of the crowd from the perspective of the whole city. The development of information and communication technology(ICT) has made it possible to the collection of large-scale, long-sequence positioning data, thus bringing many new opportunities for the study of individual's spatiotemporal behavior. Location-based service data (LBS) is a typical spatio-temporal dataset (Li and Liu, 2016), which is widely used in the field of traffic management. It can accurately identify individual activity trajectories. making it possible to study the group's daily behavior and space from the perspective of behaviorspatial interaction.

This paper takes the suburbs of Shenyang (the provincial capital city which located in the Northeast of China) as the case study area. The research collected LBS (Location Based Service) big data of 24 hours for seven 
consecutive days. Based on ST-DBSCAN clustering algorithm, the movement trajectories and stop points of 818 suburban dwellers in southern suburbs were recognized. Based on the time rhythm characteristics of working and residential behaviors, the people are classified into four typical groups: Normal-time-rhythm group, Earlytime-restricted rhythm group, Late-time-restricted-rhythm group and Dual-time-restricted-rhythm group. The spatial and temporal distribution of different behaviors on weekdays and weekends are both analysed, and the characteristics of the activities space of different types of people are calculated by quantitative index. The analysis of variance is further used to compare the differences within various groups as well as the mechanism under the difference, so as to provide certain reference for the targeted optimization of suburban occupation and housing composition, optimization of public facilities configuration, and formulation of service facility time management policies.

\section{Study Area and Datasets}

\subsection{Study Area}

Shenyang is the provincial capital city which located in the Northeast of China. It is the only megacity in the Northeast Plain in China. In 2017, the City Overall-planning determined the strategy of strengthening the coordinated development of the main city and the sub-city, and gradually guided the population from the old city within the second ring road to the main city and the sub-city outside the third ring road. The new main city of Hunnan, the western sub-city, the northern sub-city, and the eastern sub-city have become the forefront of urban incremental developing area. From the perspective of current urban construction, Shenyang presents a typical single-center pattern of loop-radiation form in road construction, the development trend of urban circle stratification is obvious. The study area in this research takes both administrative divisions and road boundaries into consideration. The dwellers whose living area located outside the city's 3rd ring road, within the southern main city, western sub-city, northern sub-city, and eastern sub-city was considered as suburban dweller The study area is shown in Figure 1.

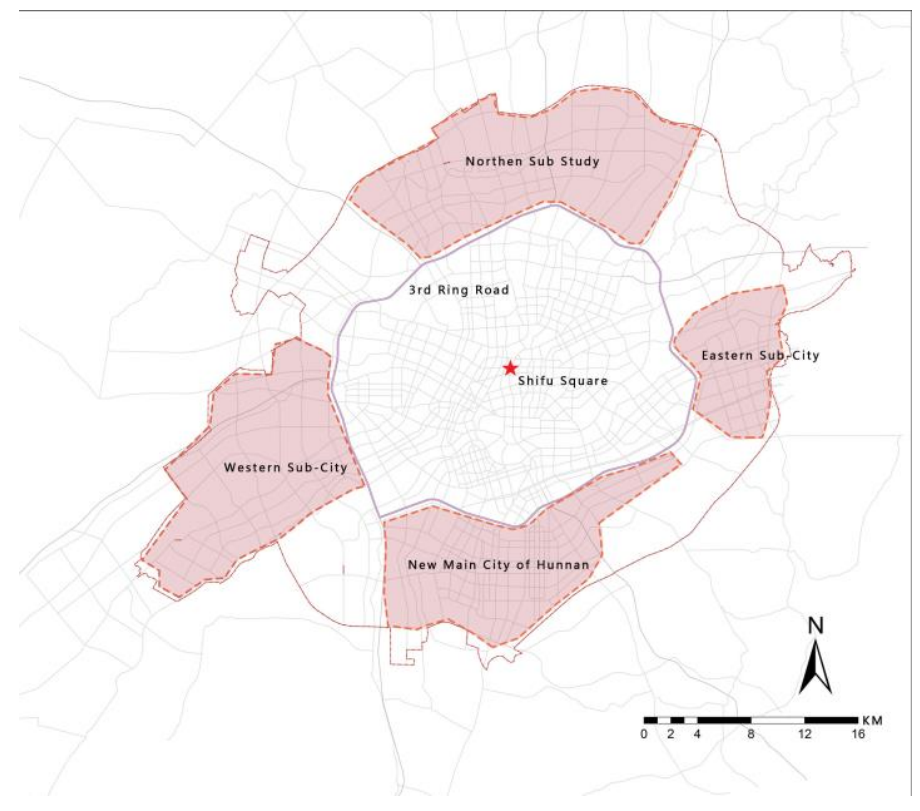

Figure 1 :Case study area

\subsection{Datasets}

The LBS positioning data used in this study is user anonymous geographic location data. Users' information has been anonymized, only containing age and gender information. The positioning data contains the date, time and latitude and longitude information of individuals. The dataset time is from October 14, 2019 to October 20, 2019 (a whole week), and the data accuracy reaches 5m. For each user's movement trajectory, 
we can form a set $P=(p 1, p 2, p 3 \ldots . p n\}$, which is the user's track point collection, The sample data is shown in the figure below. (Table 1)

Table 1 User LBS point information

\begin{tabular}{lccccccc}
\hline User number & gender & age & $\begin{array}{c}\text { Sequence } \\
\text { number }\end{array}$ & Date & Time & Longitude & Latitude \\
\hline 1255 & $\mathrm{M}$ & $36-$ & $\mathrm{p} 1$ & $2019-10-14$ & $0: 02: 32$ & 123.349748 & 41.681826 \\
& 45 & $\mathrm{p} 2$ & $2019-10-14$ & $0: 17: 15$ & 123.349763 & 41.681748 \\
& & $\mathrm{p} 3$ & $2019-10-14$ & $2: 02: 17$ & 123.349763 & 41.681748 \\
& & $\ldots \ldots$ & $\ldots \ldots$ & $\ldots \ldots$ & $\ldots \ldots$ & $\ldots \ldots .$. \\
& & $\mathrm{pm}$ & $2019-10-14$ & $23: 48: 29$ & 123.349763 & 41.681748 \\
\hline
\end{tabular}

\section{Methodology}

\subsection{Stop point identification method}

Movement and staying are both important part of the concentration of user tracing points. Recognizing the movement and staying behavior of people from the trajectory is an important perspective to deeply understand the characteristics of people's travel structure.(Schneider et al., 2013). The stop point refers to the important staying point during the moving process, usually refers to the state of being stationary or hovering in a small range for a long time(Zheng et al., 2011). From the identification of stop points in the trajectory is helpful to understand the characteristics of people's travel structure(Schneider et al., 2013) In the previous research, the speed of the trajectory point is often used to distinguish the moving behavior and the staying behavior, but it is not very effective for identifying the staying behavior for the moving trajectory that is not very clear. For example, the speed of some groups does not meet the threshold requirements, but their activities are within a certain range. Martin Ester ((Ester et al., 1996)) proposed a density-based spatial clustering method, DBSCAN (Density-Based Spatial Clustering of Applications with Noise), it clusters points based on the linear distance between two points in space and the minimum number of points. From the perspective of the extraction of trajectory data in this research, the time factor has also been taken into consideration. The method which called ST-DBSCAN which takes both spatial continuity and time continuity into consideration is used in this study. This study defines the distance threshold as 100 meters and the time threshold as 15 minutes. The specific method is to traverse the individual trajectory points to generating the stop points set. For the tracing point $\mathrm{O}_{n}$, calculate the time interval and spatial distance of the next tracing point $\mathrm{O}_{n+1}$. If the time and distance threshold limit is met, $\mathrm{O}_{n+1}$ is regarded as the adjacent point of $\mathrm{O}_{n}$, putting into the same category. Otherwise, go to the next tracing point and repeat the above steps. From the adjacent points set, a simplified new stop point is generated. The location information of the new stop point is the average of the latitude and longitude of all the tracing points in the stopping area, the start time is the occurrence time of the first tracing point in the stopping area, and the end time of the stop point is the occurrence time of the last tracing point. The result of stop point recognition is shown in Table 2.

Table 2 User LBS recognized stop point information

\begin{tabular}{cccccccc}
\hline ID & gender & age & $\begin{array}{c}\text { Stop point } \\
\text { Sequence } \\
\text { number }\end{array}$ & Date & Time & Longitude & Latitude \\
\hline 125665 & $\mathrm{M}$ & $36-$ & $\mathrm{sp1}$ & $2019-10-16$ & $0: 02: 32-6: 19: 55$ & 123.349748 & 41.681826 \\
& 45 & $\mathrm{sp2}$ & $2019-10-16$ & $7: 34: 21-10: 44: 44$ & 123.3465216 & 41.67443016 \\
& & $\mathrm{sp3}$ & $2019-10-16$ & $11: 09: 08-12: 23: 46$ & 123.349748 & 41.681826
\end{tabular}




\subsection{Stop points' behavior recognition method}

To identify people's stop points from the dataset, it is necessary to further recognized the types of activities people engage in at the stop point. People's demand for activities is the potential driving force that determines their travel. (Alvares et al., 2007)The LBS data does not contain the user's behavioral information .From the perspective of time, the travel of urban residents has a strong regularity. In this research, for stop points with strong regularity such as residential behavior and work behavior, Time-space threshold method is used to recognized, that is, if a user appears in a specific spatial range with high frequency during a specific time period, the location is judged to be the individual's residential or work area. The specific criteria in the research is as follows. For the set of stop point, the stop point whose time information intersects with that of 1:00-4:00 are screened, then cluster these points within the threshold $S=100$ meters and generate the staying area. If $80 \%$ of the points in this time period are in the area, the other point with in the same staying area are marked with the residential behavior either. The working behavior's specific time period is 9:30-11:00 in the morning and 14:30-16:00 in the afternoon, the distance threshold and the recognizing method are same with the method of residential behavior' recognition.

When it confers to the non-work behavior outside home, dwellers not only perform such activities on weekends, but may also perform such activities on the way to on and off work, or at noon on weekdays. In this research, besides the residential behavior point and working behavour point recognized above, stop points staying for more than 15 minutes are marked as non-working behavior points outside home, covering activities such as recreation, shopping, and life services activities.

\subsection{Classification methods based on the time rhythm characteristics of working and}

\section{residential behaviors}

Individual's daily behavior reflects the coordination and arrangement of the individual's daily activities, and is the result of the combined effects of individual and family characteristics, urban morphology and traffic attributes, built environment and so on. From the perspective of time, suburban dwellers travel has a strong rhythm and regularity. (Ratti, 2010)The time distribution of working-residential behavior is restricted by multiple constraints of job-residential distance, urban space and social structure, contributing richer characteristics. In this paper, a method based on the time rhythm characteristics of working and residential behaviors is adopted as the classification index of individual daily behaviors.

In the time dimension, this research first slices the distribution of the work-housing behavior of the people in the suburbs of Shenyang within 24 hours of weekdays. In the view of inflection point, From the point of inflection, residential behavior decreased significantly from 7:00 am to 9:00 am, increased significantly from 17:00 PM to 19:00 PM, relatively stable at other time points, while the working behavior were the opposite. The study defines the normal time of leaving home is from 7:00 to 9:00 and the normal time of returning home is from 17:00 to 19:00. Based on the inflection point above, this paper classifies the people according to the beginning and ending of the individual's working and residential behavior. For people who started nonresidential behaviors before 7:00, they were defined as early-out crowd, and those who started residential behavior before 17:00 were defined as early-return crowd. For those who still have residential behavior after 9:00, they are defined as late-out crowd, and for those who continue to work after 19:00, they are defined as late-return. For the stop point with behavior information set obtain in 3.2, 818 individuals with stable working and residential rhythm were selected, and proportion of each group is shown in table 3 .

Table 3 Classification result based on the time rhythm characteristics of working and residential behavior 


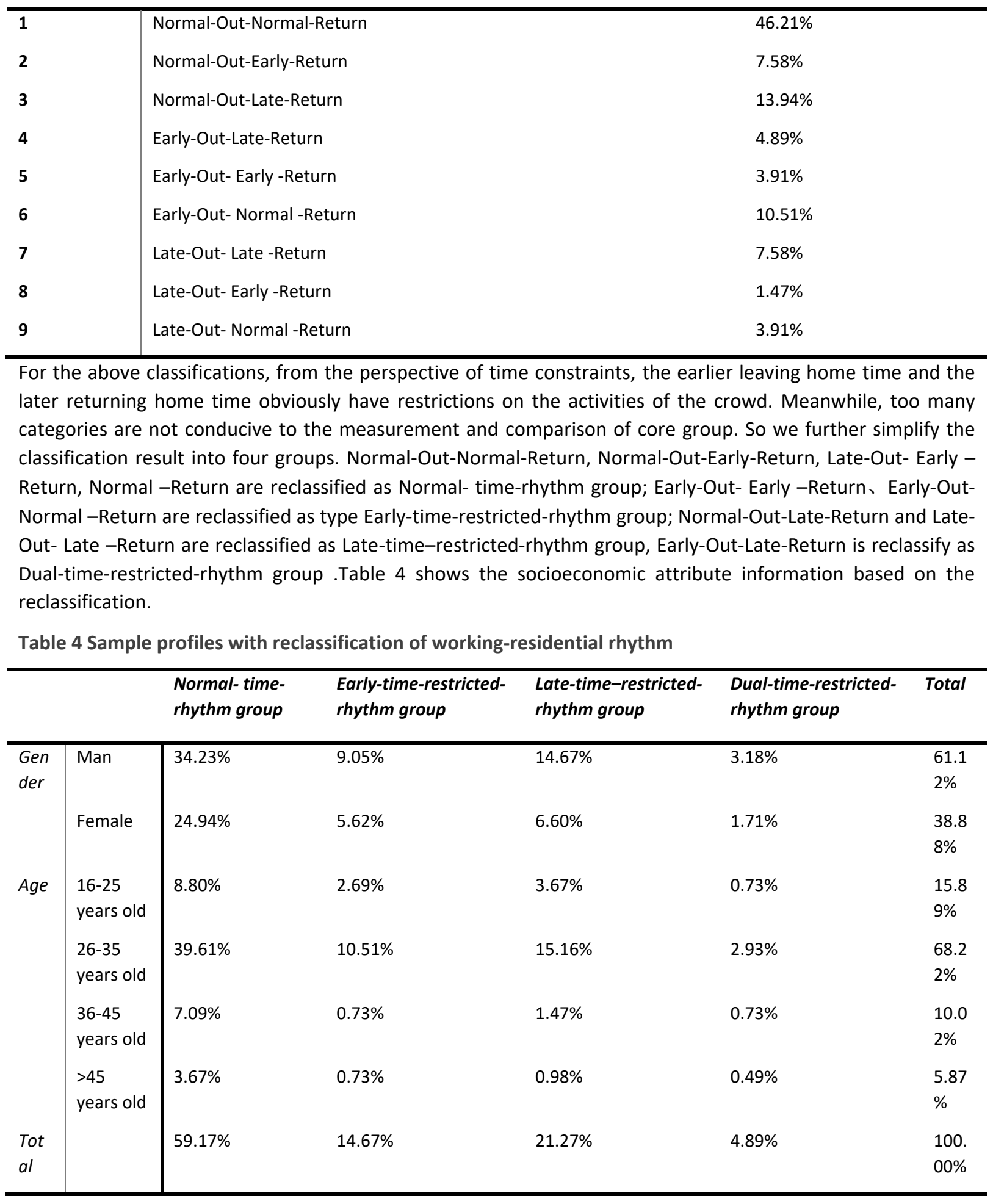

\subsection{Measuring method of residents' daily activity space}

Although the residents of different working-residential rhythm may live nearby with each other, the temporal and spatial distribution of their daily activity space may be diverse. This paper first visualizes the daily activities of different types of people to visually identify the differences in the distribution of residents' activities. Then, the method of quantitative analysis is used to measure the individual's use of urban space from different dimensions. The measurement indicators are shown in the table below. 
SUN, R.Q;SHI,Y;

Towards More Convenient Livable City: Research on the Suburban Dweller Space Using Behavior Through Spatiotemporal Big Data

Table 5 Measuring indicators of residents' daily activity space

\begin{tabular}{|c|c|}
\hline Dimension & Indicator \\
\hline Extensity & $\begin{array}{l}\text { The size of the activity space (the area of the standard confidence ellipse based on the track } \\
\text { point data) }\left(\mathrm{km}^{2}\right) \\
\text { Working distance }\end{array}$ \\
\hline Intensity & $\begin{array}{l}\text { Frequency of non-work behavior outside home } \\
\text { Total time of non-work behavior outside home ( } \mathrm{min})\end{array}$ \\
\hline Diversity & Number of places to different non-work locations outside of home \\
\hline Dependency & $\begin{array}{l}\text { Average distance between non-work behavior outside home and place of residence }(\mathrm{km}) \\
\text { Average distance between non-work behavior outside home and workplace }(\mathrm{km})\end{array}$ \\
\hline
\end{tabular}

\section{Results}

\subsection{Geo-visualization of activity space of different kind of behavior}

The result is based on the stop points with behavior tags identified in 3.2, Kernel Density is used to visualize the spatial distribution and agglomeration intensity of activities of different types of people. The detailed is shown in table6

Table 6 Spatial distribution of different behavior on weekdays and weekend.

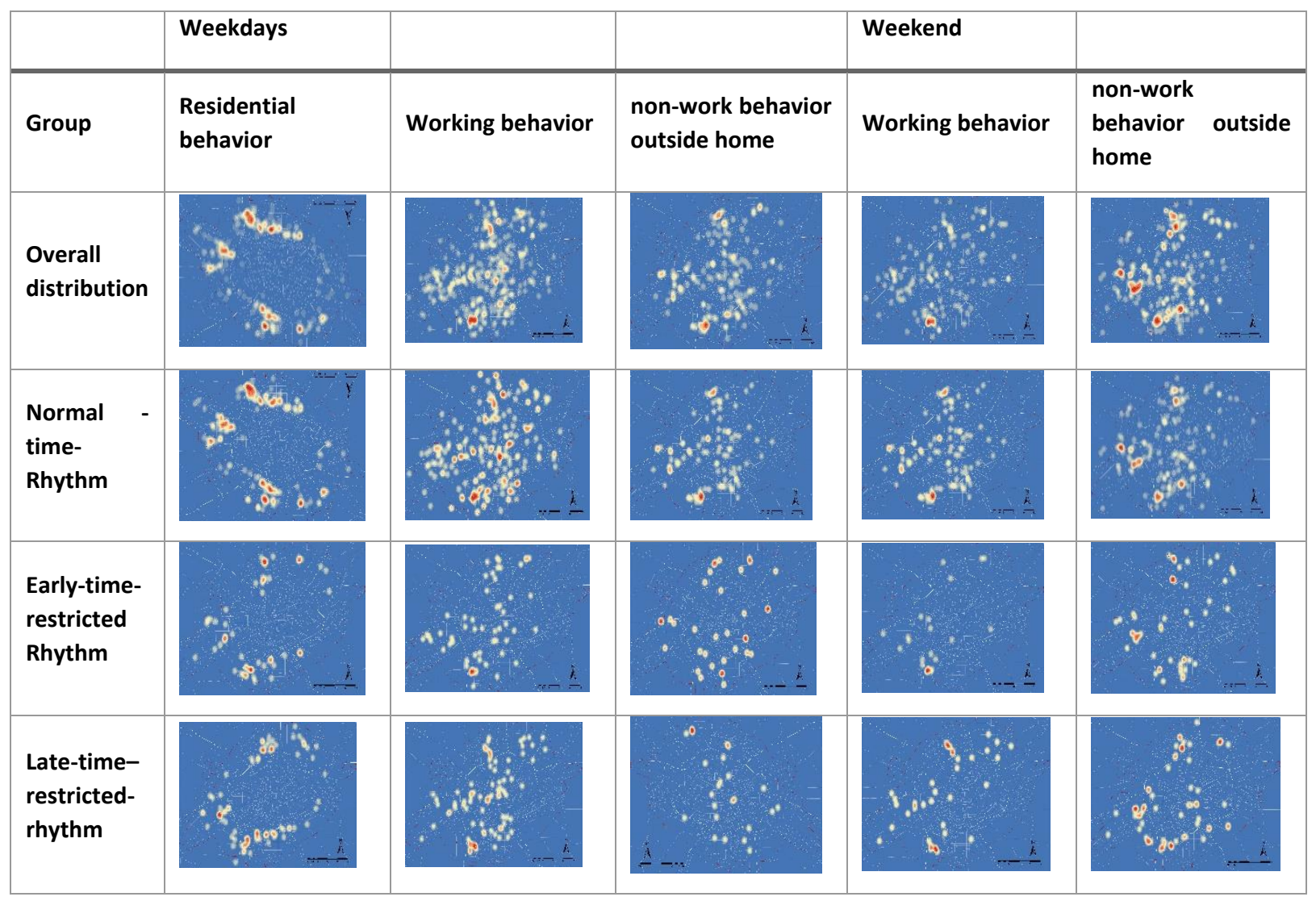




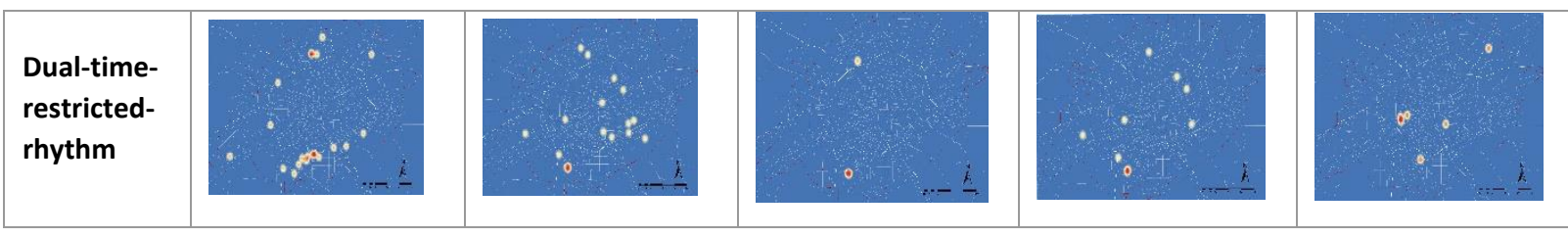

The geographic visualization above shows that for working days, compared with suburban residents with a Normal-time rhythm, Early-time-restricted or Late-time-restrict people's non-work behavior outside home seem to be more concentrated. For the Early-time-restricted rhythm group, the reason for the earlier time to leave home does not seem to be due to the long distance between working and residential area. Compared with the Late-time-restrict rhythm group, there are fewer individuals whose workplace are located in the central city, most of their working behavior is located in the suburban areas, which reflects that this group has realized the job-housing balance to some extent. From the perspective of the spatial distribution of working behavior, the working area is relatively scattered and diverse, and a small number of employment is concentrated in industrial parks dominated by machinery industry, non-ferrous metal smelting industry, chemical raw material and chemical product manufacturing industry. The spatial distribution of non-work behaviors outside the home of this type of group is mostly based on the home. When it comes to Late-timerestricted-rhythm group, the distribution of employment is similar to that of normal-time-rhythm group. For the research sample, its working locations are concentrated in the Sujiatun Industrial Park, which is dominated by traditional manufacturing and construction industries, the Jinlang area for financial commerce, scientific research and technical services, software and information technology services, and the north Shenbei University Town area. Their non-work behaviors outside the home mostly dependent on the place of work. For Dual-time-restricted-rhythm group, their employment places are mostly distributed near the eastern sub-city and Hunnan New City. Its distribution of non-work activity outside home has a significant reduction compared with other groups, reflecting the hard restriction of time on weekdays.

For weekdays as shown in Table 7, there are still $35.85 \%$ of individuals who have at least one day of working behavior on Saturday or Sunday. Compared with normal-time-rhythm group, the proportion of people with early and late time restrictions on working days has a higher proportion of weekend work, which reflects the day-to-day differences between people with different working-residential rhythm. Compared with weekdays, the intensity of none-work behavior outside home of all groups is higher, and their agglomeration in the suburburb area is more obvious, indicating that compared with the service facilities in the central city which are farther away, dwellers living in surburb still prefer to choose nearby facilities to satisfying one's own life service and recreational needs. The gathering of non-work behaviors outside the home on weekdays in the central city is more of the result of passive selection due to the location restrictions of employment positions.

Table 7 work behavior distribution at Weekend of people with different Residential-working rhythm on weekdays

\begin{tabular}{llllc}
\hline & \multicolumn{2}{c}{ Residential-working rhythm } & total \\
$\begin{array}{l}\text { Normal time- } \\
\text { Rhythm }\end{array}$ & $\begin{array}{l}\text { Early-time-restricted } \\
\text { Rhythm }\end{array}$ & $\begin{array}{l}\text { Late-time-restricted- } \\
\text { rhythm }\end{array}$ & $\begin{array}{l}\text { Dual-time-restricted- } \\
\text { rhythm }\end{array}$ & \\
\hline $31.40 \%$ & $40.00 \%$ & $42.53 \%$ & $57.50 \%$ & 36.18 \\
\end{tabular}

\subsection{The comparison of daily activity space with different residential-working rhythm}

Using the measurement method in 3.4, we calculate the indicators based on the 7-day LBS data for each participant, using the average of these metrics to represent the characteristics of activity space of each group. ANOVA analysis was used to show the differences in measures of the seven indicates during the weekdays and weekends. The statistical results are shown in table8.

In the working day, dwellers with normal rhythm or early-time-restriction rhythm have significantly higher value than other groups in terms of activity intensity and diversity. Group of Early-time-restricted rhythm have 
the longest time of none-working behavior outside the home, which to some extent shows that their behavioral characteristics of leaving early may be related to their lifestyle choices. From the perspective of the degree of dependence of non-work behavior outside home on urban space, the group of Early-time-restricted rhythm and Dual-time-restricted-rhythm are more dependent on the surrounding space of the residential area. For the group of Dual-time-restricted-rhythm, compared to the surrounding space of the residence area, they prefer to choose the surrounding area of work for life and service behavior. The four types of groups have no significant differences in the extension of the activity space.

For weekends, from the comparison of the extension of rest day activities within the group, the Normal timerhythm group and the early-time-restricted rhythm have greater activity extension than other groups, but the activity extensity of all the groups is lower than the activity extensity of the working day This shows that the location of the working area has greatly promoted the use of the functional space of the central city by suburban dwellers. Under natural conditions, individuals tend to choose life service and recreational areas nearby, and the differentiation of occupation and residence increases the diversity of urban space use to some extent. In terms of activity intensity and diversity, compared with weekdays, this indicator of the four groups has improved significantly. Compared with workdays, the living space taking home as an anchor has a larger activity radius and more types of activities.

Table 8 ANOVA result table

\begin{tabular}{|c|c|c|c|c|c|}
\hline & $\begin{array}{l}\text { Normal time- } \\
\text { Rhythm }\end{array}$ & $\begin{array}{l}\text { Early-time- } \\
\text { restricted } \\
\text { Rhythm }\end{array}$ & $\begin{array}{l}\text { Late-time- } \\
\text { restricted- } \\
\text { rhythm }\end{array}$ & $\begin{array}{l}\text { Dual-time- } \\
\text { restricted- } \\
\text { rhythm }\end{array}$ & P-value \\
\hline \multicolumn{6}{|l|}{ weekdays } \\
\hline Working distance & 7.71 & 6.84 & 7.36 & 7.93 & 0.496 \\
\hline $\begin{array}{l}\text { The size of the activity space } \\
(\mathrm{km} 2)\end{array}$ & 14.34 & 16.40 & 9.44 & 11.77 & 0.176 \\
\hline $\begin{array}{l}\text { Frequency of non-work behavior } \\
\text { outside home }\end{array}$ & 0.47 & 0.58 & 0.29 & 0.15 & $0.000^{* * *}$ \\
\hline $\begin{array}{l}\text { Number of places to different non- } \\
\text { work locations outside of home }\end{array}$ & 0.39 & 0.48 & 0.15 & 0.09 & $0.000^{* * *}$ \\
\hline $\begin{array}{l}\text { Total time of non-work behavior } \\
\text { outside home ( } \mathrm{min} \text { ) }\end{array}$ & 25.64 & 27.55 & 11.28 & 8.40 & $0.001^{* * *}$ \\
\hline $\begin{array}{l}\text { Average distance between non- } \\
\text { work behavior outside home and } \\
\text { residence }(\mathrm{km})\end{array}$ & 2.10 & 1.68 & 2.03 & 0.29 & $0.053^{*}$ \\
\hline $\begin{array}{l}\text { Average distance between non- } \\
\text { work behavior outside home } \\
\text { and workplace }(\mathrm{km})\end{array}$ & 1.75 & 2.64 & 0.83 & 0.21 & $0.000^{* * *}$ \\
\hline \multicolumn{6}{|l|}{ weekend } \\
\hline extensity & 6.27 & 7.55 & 1.33 & 4.33 & $0.080^{*}$ \\
\hline $\begin{array}{l}\text { Frequency of non-work behavior } \\
\text { outside home }\end{array}$ & 0.88 & 0.90 & 0.74 & 0.35 & $0.011^{* *}$ \\
\hline $\begin{array}{l}\text { Number of places to different non- } \\
\text { work locations outside of home }\end{array}$ & 0.79 & 0.77 & 0.69 & 0.31 & $0.014^{* * *}$ \\
\hline $\begin{array}{l}\text { Total time of non-work behavior } \\
\text { outside home ( } \mathrm{min} \text { ) }\end{array}$ & 111.42 & 103.82 & 113.37 & 51.10 & 0.181 \\
\hline Average distance between non- & 2.80 & 2.40 & 1.58 & 1.74 & $0.097^{*}$ \\
\hline
\end{tabular}




\begin{tabular}{|l|r|r|r|r|r|}
\hline $\begin{array}{l}\text { work behavior outside home and } \\
\text { residence }(\mathrm{km})\end{array}$ & & & & \\
\hline $\begin{array}{l}\text { Average distance between non- } \\
\text { work behavior outside home } \\
\text { and workplace }(\mathrm{km})\end{array}$ & 4.38 & 3.56 & 2.86 & 1.83 & $0.028^{* *}$ \\
\hline
\end{tabular}

Significantly different at:

**** $\mathrm{p}<0.01$

** $0.01<\mathrm{p}<0.05$

" $p<0.1$

For non-work behavior outside home, the temporal and spatial distribution of behavior is the result of residents' preference under the dual constraints of employment time and commuting cost. Furthermore, the non-working behavior outside the home on weekdays and weekends are sliced by hours respectively, the percentage of the total time of behavior in different periods has been calculated. The curve in figure 2 can clearly reflect the fluctuation of behavior over time. Overall, non-work behavior outside home during weekdays fluctuates more volatility, with a more obvious tendency. From the perspective of Normal- timerhythm residents, 17:00-19:00 is the active peak period of their activity, indicating that Normal- time- rhythm residents are more inclined to choose the time after work for activities. From the perspective of early-timerestricted-rhythm residents, there are two relative peaks of 6:00-8:00 and 17:00-20:00, which indicates that this group's early departure behavior is not necessarily due to employment time restraint. It may also be caused by preference of people. The earlier time to leave home may be caused by their preference for shopping and physical exercise before work. It may explain the result of the above table. For residents who leave home early, the frequency and activity time of non-work behavior outside of home have similar activity intensity to normal-time-rhythm residents. For the late-time-restricted-rhythm group, the distribution of nonwork activities outside of home on weekdays is more even, Only in the 11:00-13:00 and 17:00-19:00 dining time periods have relatively high values, which further explains the dependence of the late returnees on the service facilities of the place of employment. This is consistent with the analysis results of geographic visualization in 4.1.

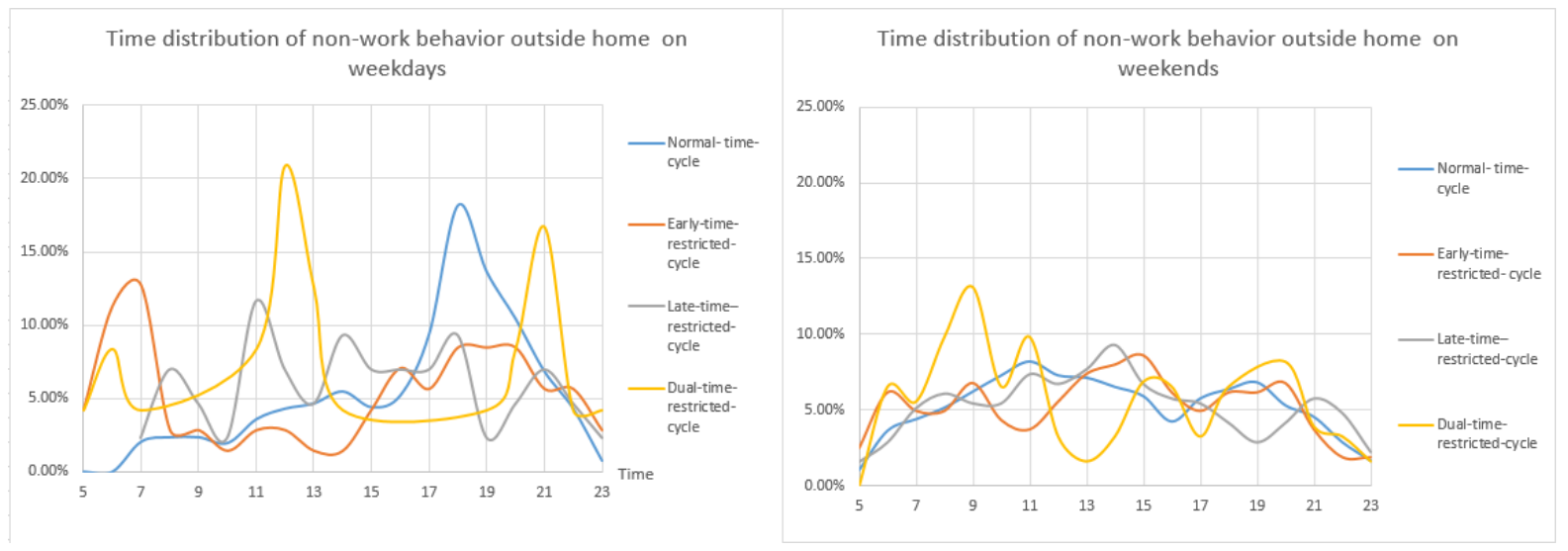

Figure 2 Time distribution of non-work behavior outside home

\section{Conclusion and discussion}

From the perspective of the people's lifestyle, this paper classifies people based on the time rhythm characteristics of working and residential behaviors, compares the temporal and spatial distribution of the people's residence behavior, working behavior, and non-work behavior outside home. The main finding is that there is indeed a difference in the using mode of urban space among the people with different time rhythm characteristics of working and residential behaviors. This temporal and spatial distribution is different in 
extensity, intensity, diversity, and spatial dependence. Similarly, its distribution is different on weekdays and weekends. The policy significance of this study is that its results can focus on the different needs of different behavior groups for urban space from the perspective of temporal and spatial behavior, so that the policy maker can provide certain suggestions and references to allocate public resource by considering time restriction into consideration. For suburban employment centers, it is necessary to fully consider the needs of the late returning group. At the same time, we should consider the matching of emerging technology industries and local residents in the aspect of industry introduction and cultivation, and pay attention to the traditional service industry that can promote the employment of disadvantaged groups near specialized, hightech employment places. For the service facilities in the residential area, it can also provide a certain reference from the time-sharing time management and content arrangement of the service facilities.

However, this research has certain limitations, and further research is needed to solve them. Firstly, this study did not subdivide non-work behavior outside home in detail. In the following research, we can use land use data and social text data to further mine the geographic semantic tags in the stop point data set to perform non-work behavior outside home. In addition, the research on the spatio-temporal differences between people is mainly based on descriptive statistics and analysis of variance. Its internal decision-making mechanism still needs further research and evaluation, in order to look forward to guiding the formulation of urban policies from the supply and demand level.

\section{Reference}

Alvares, L. O. et al. (2007) 'A model for enriching trajectories with semantic geographical information.', p. 1.

Bin, M. (2009) 'The Spatial Organization of the Separation between Jobs and Residential Locations in Beijing', Acta Geographica Sinica.

Ester, M. et al. (1996) 'A Density-Based Algorithm for Discovering Clusters in Large Spatial Databases with Noise'.

Lin, H. Z., Lo, H. P. and Chen, X. J. (2009) 'Lifestyle classifications with and without activity-travel patterns', Transportation Research Part A Policy \& Practice, 43(6), pp. 626-638.

Ratti, A. S. (2010) 'Does Urban Mobility Have a Daily Routine? Learning from the Aggregate Data of Mobile Networks', Journal of Urban Technology, 17(1), pp. 41-60.

Schneider, C. M. et al. (2013) 'Unravelling daily human mobility motifs', Journal of the Royal Society Interface, 10(84), p. 20130246.

Shen Y, Chai Y, 2013. (2013) 'Daily activity space of suburban mega-community residents in Beijing based on GPS data', Acta Geographica Sinica.

Wang, C. et al. (2003) 'A Review and Prospect on Urban Internal Spatial Structu re Research in China', Progress in Geography, 22(3).

$\mathrm{Xu}, \mathrm{Y}$. et al. (2015) 'Understanding aggregate human mobility patterns using passive mobile phone location data: a home-based approach', Transportation, 42(4), pp. 625-646.

Zhang, X. et al. (2019) 'Reside nearby, behave apart? Activity-space-based segregation among residents of various types of housing in Beijing, China', Cities, 88(MAY), pp. 166-180.

Zhang Y, C. Y. W. (2013) 'Study on suburbanization of living and activity space', Progress in Geography, 32(12), pp. 1723-1731.

Zheng, Y. et al. (2011) 'Recommending Friends and Locations Based on Individual Location History', Acm Transactions on the Web, 5(1), p. 5. 